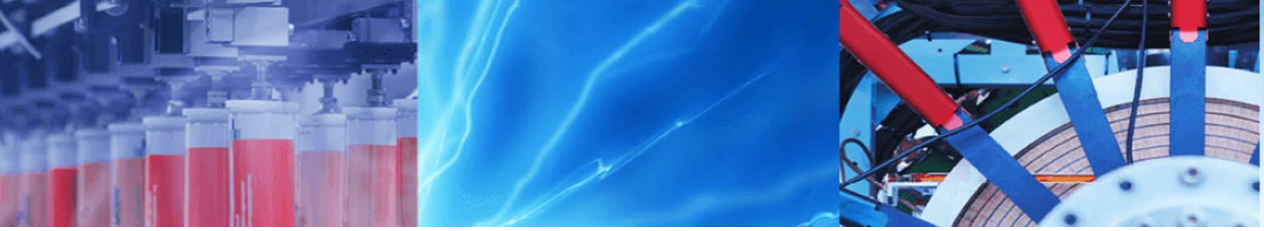

Research Article

\title{
Investigation of possible connections between solar activity and climate change in Nigeria
}

\author{
Moses Owoicho Audu ${ }^{1}$ (D) $\cdot$ Francisca Nneka Okeke ${ }^{2}$
}

() Springer Nature Switzerland AG 2019

\begin{abstract}
Over the years, several attempts were made to establish the possible link by which solar activity influenced climate change. However, the physical mechanism for these relationships has been the major challenge. In this research, we investigate the relationship between solar/geomagnetic activity and cosmic rays, the connection between cosmic rays and cloud covers and finally, cloud covers and climatic parameters. This is the proposed physical mechanism used in this study to investigate how solar activity influenced climate change in Nigeria. Sunspot number, aa index, galactic cosmic rays (GCRs), rainfall and maximum temperature data were used in this study. The time period under investigation in this study spanned for 63 years (1950-2012). Spearman's rank correlation technique was employed in analyzing the data. Results reveal that sunspot number and aa index varied in the opposite direction with GCRs based on the 11-year solar cycle. This inverse relationship was confirmed from the correlation analysis. This depicts that solar and geomagnetic activities modulate cosmic rays penetrating into the Earth's atmosphere. Furthermore, the relationship between cosmic rays and cloud covers is yet to be fully ascertained in this study. This has limited the proposed physical mechanism that this study hoped to establish. However, the variations of cloud covers with rainfall and temperature show that changes in cloud covers are associated with changes in rainfall and temperature. This study has given useful information on the possible links by which solar activity could influence climate change.
\end{abstract}

Keywords Solar activity $\cdot$ Terrestrial climate $\cdot$ Climate change $\cdot$ Climatic parameters $\cdot$ Nigeria

\section{Introduction}

It is a known fact that the Earth's climate is continuously changing. This has resulted in climate variability and extreme events such as floods, droughts, etc. Climate changes have significant impacts on humanity and the society at large [1]. The reasons for these changes, however, have always been subject of discussions and are still not well understood. The observed climate change is based on evidence from different sources, such as variations of climatic parameters, which are used as a climate change indicator [2-4]. It is worthy to note that the impacts of climate change are more pronounced now than ever before.
Climate change is affected by many factors. The effects of natural factors such as geomagnetic activity, volcanic activities, etc. and primarily of the solar activity and the associated variation of solar radiation and fluxes of galactic cosmic rays (GCRs) on the climate processes are important for understanding the physical causes of modern climate changes [5].

Studies have shown that solar variability has played a crucial role in past climate changes (e.g. $[6,7])$. Several researchers have obtained both weak and strong correlations between solar indices and climatic parameters (e.g. [8]). Also, signatures of solar activity effects were reported on variations of climatic parameters (e.g. [9-15]). However, the physical mechanism for these

$\triangle$ Moses Owoicho Audu, audumoses53@yahoo.com | 'Department of Physics, Federal University of Agriculture, Makurdi, Nigeria. ${ }^{2}$ Department of Physics and Astronomy, University of Nigeria, Nsukka, Nigeria.

SN Applied Sciences (2019) 1:149 | https://doi.org/10.1007/s42452-019-0160-x

Received: 6 September 2018 / Accepted: 2 January 2019 / Published online: 4 January 2019 
relationships has been the major challenge [16]. Several approaches have been used to investigate the physical mechanisms in Sun-climate coupling. However, incomplete understandings of solar variability, climate, and their complex interaction have been the major challenges [17].

According to Okeke [18], the interaction between the Sun and the Earth's magnetic fields is very important in understanding how solar activity influenced the Earth's atmosphere. Studies have shown that besides solar variability, variations in geomagnetic field intensity was linked to past climate changes (e.g. [19-21]). According to Kitaba et al. [22], geomagnetic activity influenced the global climate through the modulation of cosmic rays flux. Palamara [19], found out that solar-modulated geomagnetic activity is an important forcing mechanism for the recent climate change.

Several researches have been carried out to investigate whether cosmic rays could have possibly affected the Earth's climate, particularly through cloud formation. This is because galactic and solar cosmic rays influenced the physical-chemical process in the lower atmosphere $[23,24]$. Good correlation between GCRs and low clouds in contrast to middle and high clouds was reported by some authors (e.g. [25-27]), while other scholars (e.g. [28, 29]) observed that the relationship did not confirm to the previous finding.

Over the years, different approaches were used to investigate the possible mechanisms of Sun-climate coupling (e.g. [24]), however, this area is still open for more research. Hence, this study is aimed at investigating the possible connections between solar activity and terrestrial climate in Nigeria. The pathway proposed for solar-climate interaction in this study is: solar activity/geomagnetic activity $\rightarrow$ GCRs $\rightarrow$ cloud cover $\rightarrow$ climatic parameters. Therefore, the specific objectives are: (1) to determine the relationship between solar/geomagnetic activity and cosmic rays (2) to investigate the variations of GCRs with cloud covers (i.e. high, middle and low clouds) and (3) to determine the relationship between cloud covers and climatic parameters (rainfall and maximum temperatures). This research is very significant as it hopes to find out the possible link between solar activity and terrestrial climate in Nigeria.

Nigeria, located between latitude $4-14^{\circ} \mathrm{N}$ and longitude $2-15^{\circ} \mathrm{E}$, occupies an area of about $923,768 \mathrm{~km}^{2}$. It is located in West Africa close to the equator; hence, it experiences high temperature. The interplay of the tropical-continental air mass and the tropical-maritime air mass greatly influenced the atmospheric conditions in the country. Nigeria is seriously experiencing climate change like any other region of the world. These are evident in the increasing trends observed in the variability of climatic parameters (e.g. $[15,30,31])$ and an increase in extreme weather events (e.g. [32]).

\section{Sources and method of data analysis}

Sunspot numbers (SSN), geomagnetic activity aa index, cloud cover, rainfall and temperature data used in this study were obtained from the World Data Center for the sunspot index, Royal Observatory of Belgium, (http:// www.sidc.be/sunspot-data), the National Oceanic and Aeronautic Agency (http://www.ngdc.noaagov/STP/GEOMA GNETIC_DATA/aastar.shtml), the International Satellite Cloud Climatology Project (ISCCP)-D2 datasets (http:// www.isccp.giss.nasa.gov/pub/data/D2CLOUDTYPES), and Nigeria Meteorological (NIMET) Agency respectively. The SSN, rainfall and temperature data spanned for 63 years (1950-2012) while aa index and cloud cover data spanned for 61 years (1950-2010) and 26 years (1983-2009) respectively. Pressure corrected hourly cosmic rays data were obtained from Thule Neutron Monitor Station $\left(76.5^{\circ} \mathrm{N}\right.$, $68.5^{\circ} \mathrm{W}, 26.0 \mathrm{~m}$ ) with geomagnetic cut-off rigidity of $1.0 \mathrm{GV}$. The data covered a period of 56 years (1957-2012).

The data used in this study was first checked for missing data and it was further subjected to normality and homogeneity tests at the significant level of 0.05 using XLSTAT Software. The daily mean values of aa index and cosmic rays were computed by averaging the hourly values. Subsequently, the monthly and yearly mean aa index were computed from the daily mean values. The averages of the monthly mean daily SSN and cloud cover (for high, middle and low cloud covers) were computed from the monthly values. Based on the seasonal variability of rainfall and temperature in Nigeria, the country was sub-divided into the northern region (R1), south eastern region (R2) and south western region (R3), while the average of all the regions is denoted as $R_{\text {all }}$. Meteorological stations and their coordinates in each region are shown in Table 1. The daily rainfall and temperature were used to compute the monthly mean values for each station. This was then average for all the stations in each region. Finally, correlation analysis was performed using Spearman's rank correlation technique at a significant level of 0.05 using Special Programme for Social Sciences (SPSS). It is worthy to note that the data used in this study were not evenly spanned; hence, they were harmonized to the same period in all the analysis. Also, we used global cloud cover data, since there is no cloud cover data for high, middle and low clouds in Nigeria. 
Table 1 Meteorological stations and their geographic co-ordinates

\begin{tabular}{llrr}
\hline Regions & Stations & Lat. $\left(^{\circ}\right)$ & Long. $\left(^{\circ}\right)$ \\
\hline Region 1 (northern region) & Maiduguri & $11.83 \mathrm{~N}$ & $13.15 \mathrm{E}$ \\
& Sokoto & $13.07 \mathrm{~N}$ & $5.23 \mathrm{E}$ \\
& Bauchi & $10.28 \mathrm{~N}$ & $9.82 \mathrm{E}$ \\
& Kano & $12.05 \mathrm{~N}$ & $8.53 \mathrm{E}$ \\
& Kaduna & $10.52 \mathrm{~N}$ & $7.43 \mathrm{E}$ \\
Region 2 (south eastern region) & Enugu & $6.47 \mathrm{~N}$ & $5.57 \mathrm{E}$ \\
& Owerri & $5.48 \mathrm{~N}$ & $7.02 \mathrm{E}$ \\
& Calabar & $4.95 \mathrm{~N}$ & $8.32 \mathrm{E}$ \\
& Port-Harcour & $4.75 \mathrm{~N}$ & $7.00 \mathrm{E}$ \\
& Warri & $5.52 \mathrm{~N}$ & $5.73 \mathrm{E}$ \\
Region 3 (south western region) & Ikeja & $6.45 \mathrm{~N}$ & $3.43 \mathrm{E}$ \\
& Benin & $6.23 \mathrm{~N}$ & $5.60 \mathrm{E}$ \\
& Oshogbo & $7.78 \mathrm{~N}$ & $4.48 \mathrm{E}$ \\
& Ibadan & $7.38 \mathrm{~N}$ & $3.98 \mathrm{E}$ \\
& llorin & $8.50 \mathrm{~N}$ & $4.60 \mathrm{E}$ \\
\hline
\end{tabular}

\section{Results and discussion}

Results of the analysis show that there was no missing data in the period under investigation. Also, the normality and homogeneity tests show that the data followed a normal distribution and are also homogenous. From Fig. 1a, it could be observed that sunspot number varies in the opposite direction with cosmic rays. This inverse relationship was also observed in the variations of aa index with cosmic rays (Fig. 1b). Correlation analysis was performed to ascertain the level of the association. Sunspot number and aa index were strongly but negatively correlated with cosmic rays with a correlation coefficient of -0.843 and -0.686 respectively. This indicates that an increase in solar and geomagnetic activities lead to a decrease in cosmic rays penetrating the Earth's atmosphere and vice versa. This could be attributed to the modulation of GCRs by solar and geomagnetic activities. Researchers have shown that the propagation and modulation of GCRs are determined within the heliosphere by their interaction with geomagnetic fields frozen in the solar wind and in a coronal mass ejection with accompanying interplanetary shock waves [33]. According to Palle and Butler [27], it is feasible that cosmic rays may provide the link whereby solar activity affects the global climate.

It could be observed from Fig. 2a that cosmic rays and high cloud cover varied in the same direction from 1983 to 1989 . This depicts that they have a good relationship, while from 1989 to 1991, both varied in the opposite direction, which implies an inverse relationship. They also vary in the opposite direction from 1991 to 2002 and then increases in the same direction until 2009. Similarly, from 1983 to 2002, middle cloud cover and GCRs have a
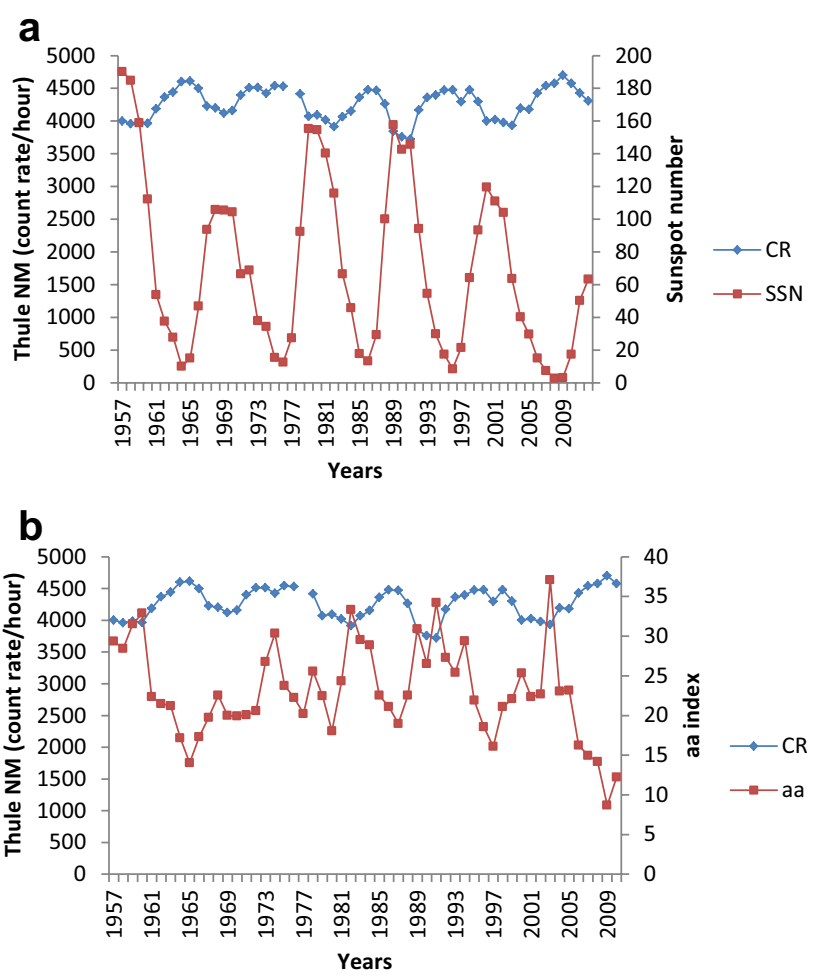

Fig. 1 Comparison between variations of yearly mean a cosmic rays and sunspot number (1957-2012) b cosmic rays and aa index (1957-2010)

good relationship, but both increases in the same direction until 2009 (Fig. 2b), while low cloud cover has the same pattern of variations with cosmic rays from 1983 to 1995, but diverges from 1995 and decreases steadily until 2009 (Fig. 2c). This finding is similar to the reports of other researchers (e.g. [25-29]).

It was proposed in the GCR-cloud hypothesis that cosmic rays influence low clouds in contrast to middle and high clouds (e.g. [29]). However, from this result, the reverse is the case in recent decades. This may probably be attributed to the irregular variability observed in the recent solar cycles during the period under study. Therefore, the relationship between cosmic rays and cloud covers as proposed in the GCR-cloud hypothesis is yet to be established in this study. Base on this, it implies that the proposed pathway to investigate solar-climate interaction in this study could not be established. Hence, the possible solar-climate connection is yet to be fully confirmed from this study.

From the variations of high cloud cover with rainfall in $\mathrm{R} 1$ and R2 (Figs. 3a, 4a), it depicts that no relationship exists between them. This implies that high cloud cover has little or no influence on rainfall in Nigeria. It is interesting to note that high cloud is composed mainly of ice crystals which do not support the formation of rainfall 
Fig. 2 Relationship between variations of yearly mean cosmic rays with $\mathbf{a}$ high $\mathbf{b}$ middle and $\mathbf{c}$ low cloud cover (1983-2009)

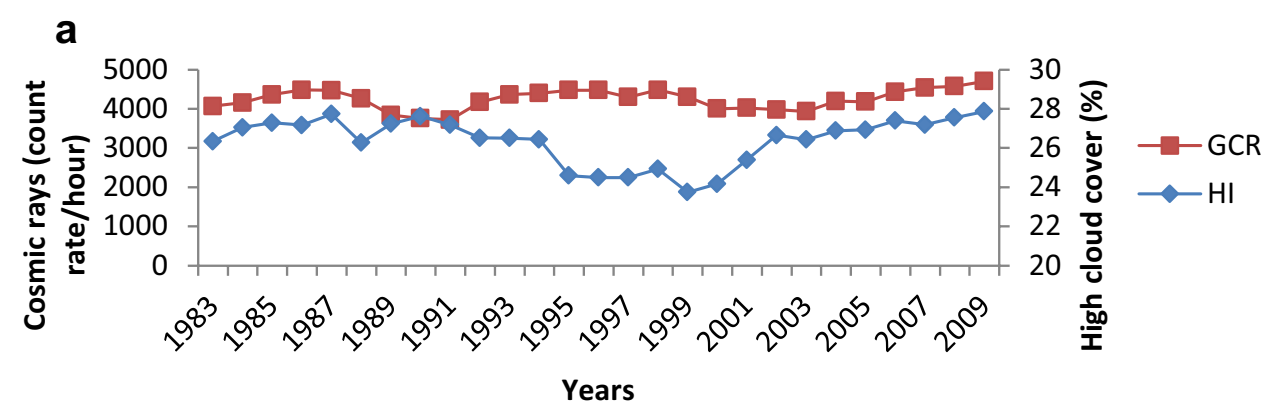

b
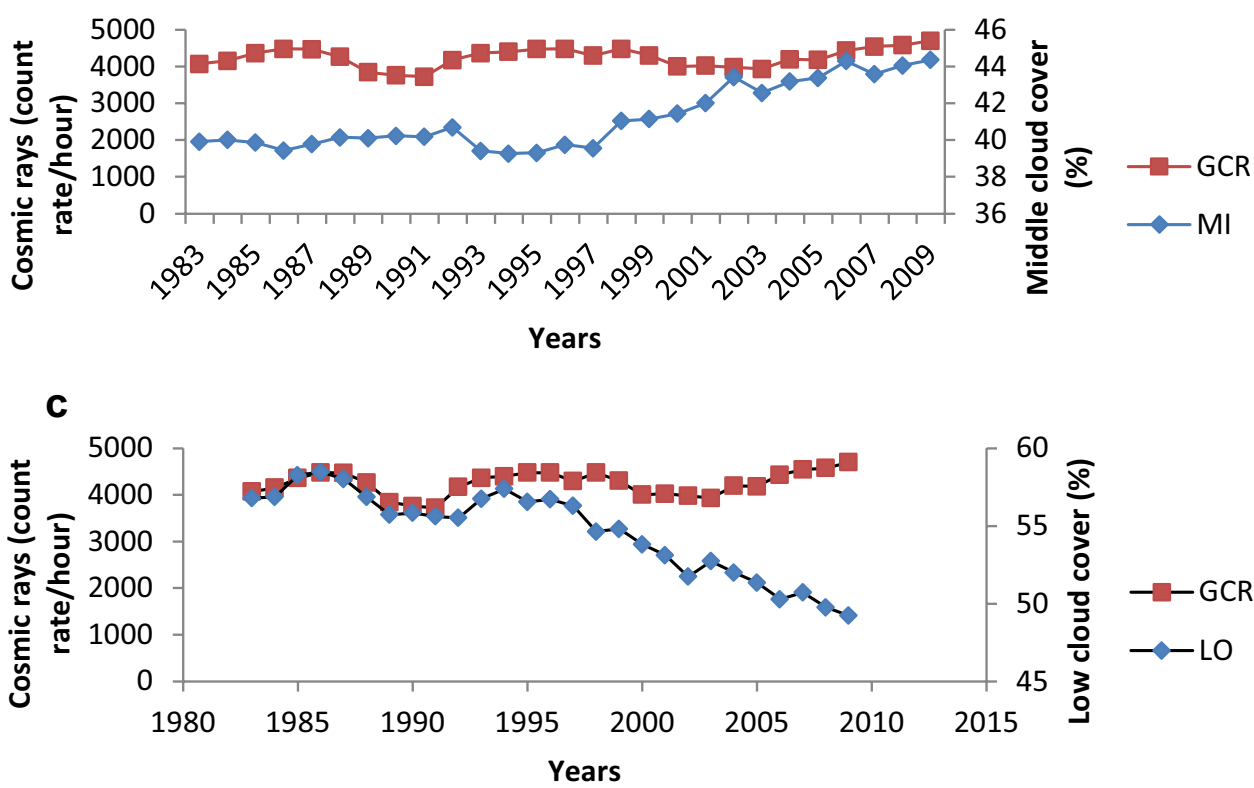

[29]. Similarly, the middle cloud cover was observed to vary in the opposite direction with rainfall in R1 and R2 (Figs. 3b, 4b). This shows that it has no much effect on rainfall. This may be due to its composition of ice crystals, water vapour, and supercooled water droplets.

On the other hand, low cloud cover varied in the same directions with rainfall in R1 and R2 (Figs. 3c, 4c). This implies that low cloud cover may influence rainfall. It has been reported that among the different cloud types, the highest long-term association between water content and cloud cover is apparently seen in relation to low cloud, with other cloud types showing little association. Also, low cloud is the only recognized rain-producing clouds, since it composes primarily of liquid water droplets with a high amount of cloud condensation nuclei; necessary for cloud formation and subsequently rainfall $[25,26]$. This could be the possible explanation for the relationship between low clouds and rainfall observed in this study. Similar results were also obtained between cloud covers and rainfall in R3 and $\mathrm{R}_{\mathrm{all}}$ (figures not shown).
To investigate the relationship between cloud cover and temperature, Spearman's rank correlation technique was employed. The correlation coefficients of $0.469,0.189$, 0.189 and 0.427 were obtained in the correlation of high cloud cover with maximum temperature in R1, R2, R3, and $R_{\text {all }}$ respectively (Table 2 ). This shows that high cloud cover is directly related to temperature; that is, the presence of high clouds leads to an increase in temperature. This may be due to the fact that high thin clouds tend to transmit incoming solar radiation to the Earth's surface but trap outgoing infrared radiation, causing it to have a low albedo. It thus contributes to the greenhouse effect. A high correlation was observed in $\mathrm{R} 1$ and $\mathrm{R}_{\mathrm{all}}$. This could be attributed to the location of R1 close to the Sahara desert and $R_{\text {all }}$ at the equator. The atmospheric conditions in R1 is mostly cloudless due to the influence of the Sahara desert, hence the high temperature experienced in this region (R1). Based on the location of $R_{a l l}$ at the equator, it experiences high temperature due to the fact that the Sun is overhead throughout West Africa. The region of West Africa is heated intensely as a result of the increased 

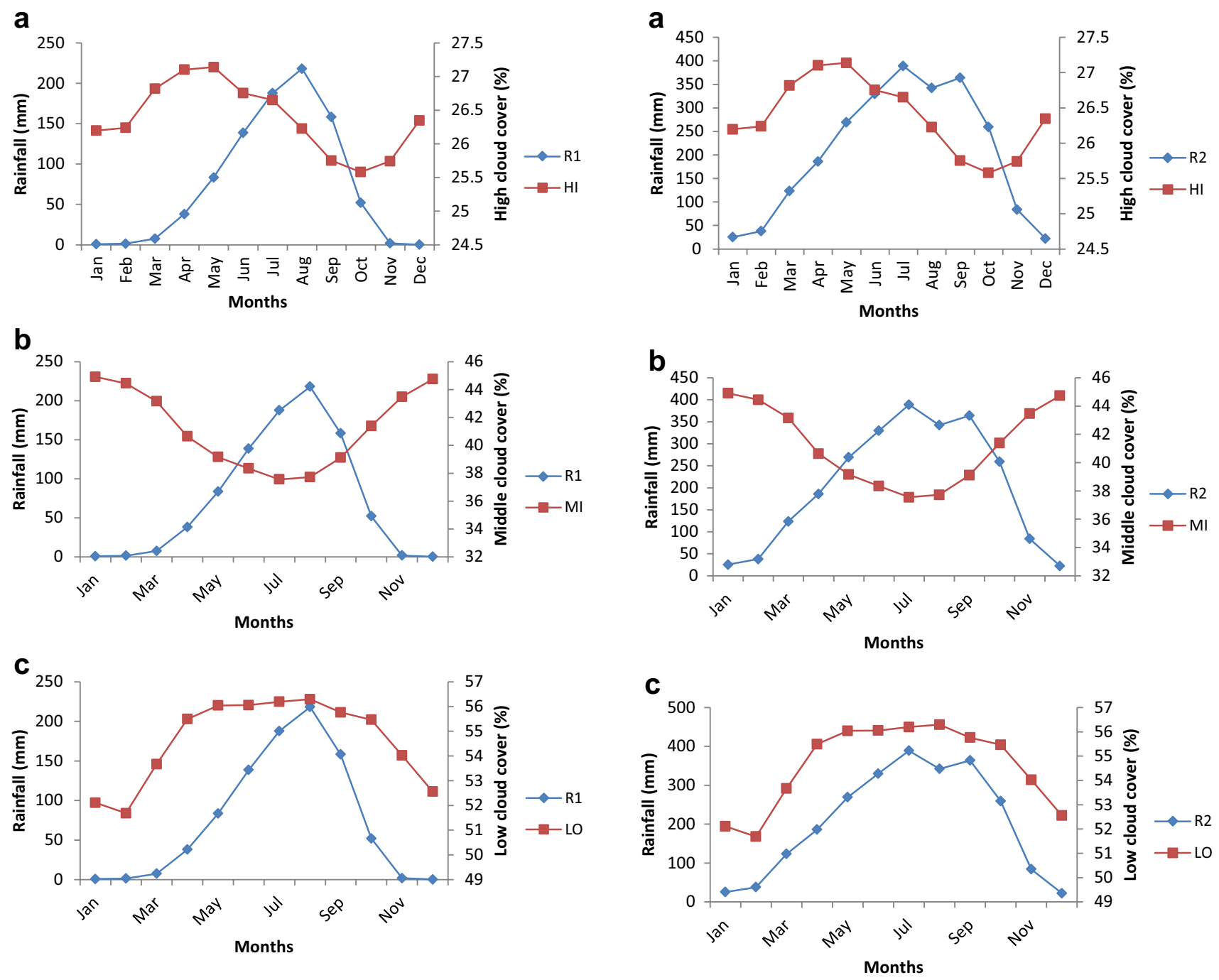

Fig. 3 Variations of monthly mean rainfall in R1 with $\mathbf{a}$ high $\mathbf{b}$ middle and c low cloud covers (1983-2009)

insolation received from the Sun, hence the high temperature experienced in $\mathrm{R}_{\text {all }}$.

The correlation coefficient of middle cloud cover with maximum temperature in $\mathrm{R} 1, \mathrm{R} 2, \mathrm{R} 3$, and $\mathrm{R}_{\text {all }}$ were 0.357 , $0.832,0.832$ and 0.615 respectively (Table 2 ). This shows that very strong and positive correlations were obtained in $\mathrm{R} 2, \mathrm{R} 3$, and $\mathrm{R}_{\mathrm{all}}$, while positive but weak relationship was recorded in $\mathrm{R} 1$. This may probably be due to the composition of Middle clouds. It is composed of water, ice crystals, and supercooled water droplets. The high relationship between middle clouds and R2, R3 and $R_{\text {all }}$ may imply that middle clouds are always present when high temperature is recorded in these regions. It shows that middle clouds may not have much effect in reflecting incoming solar radiation because of its composition.

On the other hand, low cloud cover was negatively but strongly correlated with temperature in $R 2, R 3$ and $R_{\text {all }}$ with

Fig. 4 Variations of monthly mean rainfall in $\mathrm{R} 2$ with $\mathbf{a}$ high $\mathbf{b}$ middle and c low cloud covers (1983-2009)

Table 2 Correlation coefficient ( $r$ ) of monthly mean maximum temperature with cloud covers (1983-2009)

\begin{tabular}{lllll}
\hline Temperature & Regions & \multicolumn{3}{l}{ Cloud type } \\
\cline { 3 - 5 } & & High & Middle & Low \\
\hline $\begin{array}{c}\text { Maximum tem- } \\
\text { perature }\left({ }^{\circ} \mathrm{C}\right)\end{array}$ & $\mathrm{R} 1$ & 0.469 & 0.357 & -0.399 \\
& $\mathrm{R} 2$ & 0.189 & 0.832 & -0.888 \\
& $\mathrm{R} 3$ & 0.189 & 0.832 & -0.888 \\
& $\mathrm{R}_{\mathrm{all}}$ & 0.413 & 0.594 & -0.636 \\
\hline
\end{tabular}

a correlation coefficient of $-0.888,-0.888$ and -0.657 respectively, while it was negatively and weakly correlated with temperature in R1 (Table 2). This implies that an increase in low cloud cover leads to a decrease in temperature and vice versa in R2, R3, and $\mathrm{R}_{\mathrm{all}}$. On the contrary, 
low cloud cover is inversely related to temperature in $\mathrm{R} 1$; however, it depicts that it is not the determinant factor controlling the variations of maximum temperature in this region. This may be due to the high albedo of low cloud. The high correlations obtained in R2, R3, and $\mathrm{R}_{\text {all }}$ may be due to the fact that low thick clouds primarily reflect incoming solar radiation; causing it to have a very high albedo. Hence, the low temperature observed in R2, R3, and $R_{\text {all }}$. This shows that low clouds were the determinant factor controlling maximum temperature in R2 and R3. This may be due to the influence of the Atlantic Ocean in these regions, making the areas to be cloudy most often. This reflects much solar radiation back to space, leading to a low surface temperature of the Earth. This result is in line with the observations of Nastos [34], who reported that clouds with low bases reduced maximum air temperature, because they are very effective in reflecting sunlight, middle clouds have moderate decreasing effects, while high clouds have increasing effects on the air temperature, because they consist of ice-crystal which absorb more longwave radiation emitted by the Earth surface.

\section{Conclusion}

The following conclusions were drawn from this study:

- Sunspot number and aa index varied in opposite direction with GCRs based on the 11-year solar cycle. This inverse relationship was confirmed from the correlation analysis at the significant level of 0.05 .

- Cosmic rays have a good relationship with low cloud cover from 1983 to 1995 in contrast to high and middle cloud cover, while the reverse was the case from 1995 to 2009.

- Based on this result, the connection between solar/ geomagnetic activities with climatic parameters is yet to be fully confirmed.

- Low clouds have a significant correlation with rainfall, in contrast to high and middle clouds due to its composition.

- Changes in cloud covers are associated with changes in temperature.

- This study has given information on the possible links by which solar activity could influence the terrestrial climate.

- It is hereby recommended that solar indices (e.g. solar flares, Kp index, Dst, etc.) and climatic parameters (e.g. solar radiation, relative humidity, minimum temperature, average temperature, etc.) should be employed in further analysis. Also, cloud cover data for high, middle and low clouds for Nigeria should be made available and used in subsequent work rather than the global data used in this study.

Acknowledgements The authors thank the Nigeria Meteorological (NIMET) Agency, for providing the rainfall and temperature data, the World Data Center for the sunspot index, Royal Observatory of Belgium, for providing sunspot number data, the Thule Neutron Monitor Station for cosmic ray data and the National Centers for Environmental Information for the geomagnetic activity aa index data. We are also grateful to the anonymous reviewers for their observation, suggestions, and comments that have improved the original manuscript.

\section{Compliance with ethical standards}

Conflict of interest The authors declare that they have no conflict of interest.

\section{References}

1. Manton MJ, Della-Marta PM, Haylock MR et al (2001) Trends in extreme daily rainfall and temperature in Southeast Asia and South Pacific: 1961-1998. Int J Climatol 21:269-284

2. EI Mallah ES, El sharkawy SG (2011) Influence of circulation indices upon winter temperature variability in Egypt. J Atmos Sol Terr Phys 73:439-448

3. IPCC (Intergovernmental Panel on Climate Change) (2013) Climate change: the physical science basis. Working group 1 contribution to the IPCC fifth assessment report. Cambridge University Press, Cambridge, UK, pp 36-40

4. Akisanola AA, Ogunjobi KO (2014) Analysis of rainfall and temperature variability over Nigeria. Glob J Hum Soc Sci 14(3):1-17

5. Dergachev VA, Dmitriev PB, Raspopov OM, Van Geel B (2004) The effects of galactic cosmic rays modulated by solar terrestrial magnetic fields on the climate. Russia J Earth Sci 6(5):323-338

6. Lockwood M, Stamper R (1999) Long-term drift of the coronal source magnetic flux and the total solar irradiance. Geophys Res Lett 26:2461-2464

7. Okeke FN, Audu MO (2017) Influence of solar and geomagnetic activities on climate change in Nigeria. Int J Phys Sci 12(15):184-193

8. Valev D (2006) Statistical relationship between the surface air temperature anomalies and the solar and geomagnetic activity indices. Phys Chem Earth 31:109-112

9. Dobrica V, Demetrescu C, Boroneant C, Maris G (2009) Solar and geomagnetic activity effects on climate at regional and global scales: case study-Romania. J Atmos Sol Terr Phys 71(17-18):1727-1735

10. El-Borie MA, Abdel-Halim AA, Shafik E, El-Monier SY (2011) Possibility of a physical connection between solar variability and global temperature change throughout the period 1970-2008. IJRRAS 6(3):296-301

11. El-Borie MA, Abd El-Zaher M, El-Monier S (2012) Studying of the solar-climate interaction in Canada. World Environ 2(2):16-23

12. El-Borie MA, Abd-El Zaher M, Al Shenawy A (2012) Solar and geomagnetic activity effects on global surface temperatures. Am J Environ Eng 2(4):80-85

13. El Mallah ES, Abdel-Halim AA, Thabit A, El-Borie MA (2012) Solar and geomagnetic activity effects on Egypt's climate. Int J Environ Sci 2(3):1807-1817 
14. Olusegun CF, Rabiu AB, Ndeda JOH, Okogbue EC (2014) Trends of temperature and signature of solar activity in selected stations in Nigeria. Atmos Clim Sci 4:171-178

15. Audu MO, Okeke FN, Okoro EC (2017) Variability of maximum temperature and its decadal anomaly over Nigeria: possible connection with Solar and geomagnetic activities. IntJ Phys Sci 12(14):163-174

16. Laut P (2003) Solar activity and terrestrial climate: an analysis of some purported correlations. J Atmos Sol Terr Phys 65(2003):801-812

17. National Research Council (NRC) (2012) The effects of solar variability on Earth's climate. A workshop report. The National Academic Press, Washington D. C. www.nap.edu. Accessed 28 Mar 2017

18. Okeke FN (2015) Understanding the science of climate change in Africa. Sci Policy Afr Newsl Afr Acad Sci 19(14):10

19. Palamara D (2003) Solar activity and recent climate change: evaluating the impact of geomagnetic activity on atmospheric circulation. Ph.D. thesis, School of Geosciences, University of Wollongong

20. Courtillot C, Gallet Y, Le Mouel J, Fluteau F, Genevey A (2007) Are there connections between the Earth's magnetic field and climate? Earth Planet Sci Lett 253(2007):328-339

21. Dergachev VA, Vasiliev SS, Rasppopov OM, Jungner H (2012) Impact of the geomagnetic field and solar radiation on climate change. Geomagn Aeron 52(8):959-976

22. Kitaba I, Hyodoa M, Katohb S, Dettmanc DL, Satod H (2013) Midlatitude cooling caused by geomagnetic field minimum during polarity reversal. PNAS 110(4):1215-1220

23. Svensmark H, Friis-Christensen E (1997) Variation of cosmic ray flux and global cloud coverage-a missing link in solar-climate relationships. J Atmos Sol Terr Phys 59:1225-1232

24. Joe G (2012) Heliospheric phenomena responsible for cosmic ray modulation at the Earth in the effects of solar variability on
Earth's climate. A workshop report. National Academic Press, Washington, D. C.

25. Marsh N, Svensmark H (2000) Cosmic rays, clouds, and climate. Space Sci Rev 94:215-230

26. Yu F (2002) Altitude variations of cosmic ray induced production of aerosols: implications for global cloudiness and climate. J Geophys Res 107(A7):1-8

27. Palle $E$, Butler CJ (2000) The influence of cosmic rays on terrestrial clouds and global warming. Astron Geophys 42(4):18-22

28. Kristjansson JE, Staple A, Kristiansen J (2002) A new look at possible connections between solar activity, clouds, and climate. Geophys Res Lett 29(23):1-4

29. Agee EM, Kiefer K, Cornett E (2012) Relationship of lower-troposphere cloud cover and cosmic rays: an updated perspective. Am Meteorol Soc 25:1057-1060

30. Audu MO, Okeke FN (2018) Seasonal variability of rainfall and its decadal anomaly over Nigeria: possible role of solar and geomagnetic activities. Int J Adv Eng Res Sci 5(9):325-335

31. Otun JA, Adewumi JK (2009) Rainfall variability and drought inference in the Sudano-Sahelian region of Nigeria. J Nat Sci Eng Technol 8(2):44-55

32. Nsikak B, Chisom N, Akan W, Adebusayo A, Omowunmi F (2017) Changes in diurnal temperature and precipitation extremes in North Central Nigeria. In: The 2nd international electronic conference on atmospheric sciences (ECAS 2017), Sciforum electronic conference series, 16-31 July 2017, vol 2

33. Dorman LI (2012) Cosmic ray and space weather: effects on global climate change. Ann Geophys 30:9-19

34. Nastos PT (2008) Effects of clouds on air temperature in Athens, Greece. Trends and variability. In: 8th annual meeting of the EMS/7th ECAC. EMS8/ECAC7, vol 5 (Abstract) 